\title{
Effect of Phase Compatibility on the Foaming Behavior of LDPE/HDPE and LDPE/PP Blends with Subcritical $\mathrm{CO}_{2}$ as the Blowing Agent
}

Chen Wan ${ }^{\mathrm{a}}$, Gangwei Sun ${ }^{\mathrm{b}}$, Feng Gao ${ }^{\mathrm{a}}$, Tao Liu ${ }^{* a}$, Mohamed Esseghir ${ }^{*}$, Ling Zhao ${ }^{\mathrm{a}}$ and Weikang Yuan ${ }^{\mathrm{a}}$

a: Shanghai Key Laboratory of Multiphase Materials Chemical Engineering, East China University of Science and Technology, Shanghai 200237, P. R. China.

b: Dow Chemical China Co Ltd, Elastomers, Electrical \& Telecommunication R\&D, Shanghai 201203, P. R. China

c: Dow Chemical Company, Elastomers, Electrical \& Telecommunication R\&D, Collegeville, PA 19426, USA.

* Corresponding author. Tel.: +86 21 64253470; fax: +86 2164253528.

Tel.: 610-244-7089; fax: 610-244-6144

E-mail: liutao@ecust.edu.cn (T. Liu), esseghm@dow.com (M. Esseghir) 


\section{Abstract}

Low Density Polyethylene (LDPE) is blended with High Density Polyethylene (HDPE) and three types of Polypropylene (PP) having different melting index (MI), respectively. The compatibility of LDPE/HDPE blends is characterized by using thermal analysis and rheology methods. Differential scanning calorimeter (DSC) traces and rheology methods confirmed their good compatibility. For LDPE/PP blends, the incompatibility has been widely acknowledged in the literature. The distribution of the PP phase in the blend is investigated using polarized optical microscopy (POM). It is found that the phase structure is closely related to the blend composition and the viscosity ratio of the blend components. Extrusion foaming of the blends is conducted using a single extruder fitted with a $\mathrm{CO}_{2}$ gas injection system. Under similar foaming conditions, the compatible LDPE/HDPE blends all generated a uniform cell morphology and achieved roughly the same expansion ratio. Although the incompatible interface is beneficial to cell nucleation, the LDPE/PP blends did not achieve satisfactory foaming performance. To determine the differences in the foaming behavior of the two blends, the viscoelastic properties and diffusion coefficients of supercritical $\mathrm{CO}_{2}$ in the blends, were accurately measured via rheology and magnetic suspension balance (MSB) methods. The results indicate that the viscoelastic properties did not show a dominant role in determining the foaming behavior, by contrast, $\mathrm{CO}_{2}$ diffusion is found to be the key factor affecting foaming performance especially in the case of a co-continuous phase structure.

Keywords: LDPE blend, compatibility, extrusion foaming, rheology, $\mathrm{CO}_{2}$ diffusion 


\section{Introduction}

In comparison to solid polymers, microcellular polymeric foams possess a number of advantages such as light weight, high impact resistance and toughness, high stiffness-to-weight ratio and low thermal conductivity [1-3]. Polyolefins, especially polyethylene (PE) and polypropylene (PP), have been widely used due to their relative low density, good chemical resistance, electrical insulation properties, and low cost. It is therefore desirable to prepare superior polyolefin foams for use in applications such as packaging, pipe, wire \& cable and other insulation materials [4, 5].

Low density polyethylene (LDPE) is generally used for foaming mainly due to its long-chain branches distributed along and extending from the polymer backbone [6]. These branches make the individual LDPE molecule difficult to slide over each other, which increases the resistance of the molten polymer to stretching during elongation. However, its relatively poor thermal resistance and mechanical properties limit the applications of LDPE. Other linear polyolefin resins such as high density polyethylene (HDPE), linear low density polyethylene (LLDPE) and isotactic PP have superior mechanical properties but are difficult to foam due to their low melt strength which cannot sustain cell growth during the foaming process. Many efforts have been made to produce foams from these so-called linear resins [7, 8], in which a "two-stage-process" including cross-linking and radiation were used. In such approaches, some gel formation might occur, which is undesirable for the finished product $[9,10]$. Blending LDPE with other high temperature resistance polymers is an 
effective method to couple their merits together.

A number of researchers have focused on polymer blends foaming by using batch, semi-continuous and continuous processes, respectively [11-20]. The batch foaming process is a convenient and easy method to study the effects of compatibility, phase morphology and blend composition on foaming. Moreover, the process provides flexibility in adjusting the foaming conditions. The foaming temperature can be set far below the melting temperature $\left(T_{\mathrm{m}}\right)$ of the polymer, and the process can be pressure quenching or temperature rising [21, 22]. By contrast, in the continuous process, the polymer/ $\mathrm{CO}_{2}$ mixture should be maintained at molten state to prevent clogging of the extruder $[12,14]$. Zhai et al. employed PP-gr-polystyrene with different polystyrene (PS) graft chain lengths to improve the interfacial compatibility of PP/PS blends. They found that the increase in the interfacial compatibility decreased gas escape and enabled higher retention of foaming gas for cell growth [23]. However, in their work, the blend composition is fixed so that the phase structure is adjusted via the use of the compatibilizers. The effect of the phase structure or blend compatibility on the foaming behavior is not studied. Liao et al. investigated the effect of interface and phase structure on the bubble nucleation and porous morphologies based on a typical immiscible system, i.e., poly(lactic acid) (PLA)/polystyrene (PS) blends [19]. Zhang et al. prepared LLDPE/PS blends with sea-island and co-continuous morphology by varying the compositions. They found that the sea-island phase structure of the copolymers has no obvious influence on the foaming behavior of the blends, while the co-continuous structure improved the foam 
morphology of the blends [20]. Siripurapu et al. blended polyvinylidene fluoride (PVDF) with PS and polymethyl methacrylate (PMMA) for extrusion foaming. The results showed that the miscible PVDF/PMMA characterized by DSC can achieve excellent cell morphology while the immiscible PVDF/PS performed poorly in foaming [17]. In all the work, however, the rheological properties and the $\mathrm{CO}_{2}$ diffusivity were not studied or related to the foaming behavior of the polymer blends.

Most polymer blends are incompatible due to large solubility differences which lead to poor interfacial adhesion. In addition, especially in typical industrial applications, polymer blend manufacturing is achieved by melt compounding such as in a twin-screw extruder rather than intimate solution blending due to cost, flexibility and amount of solvent required. Thus, it is almost impossible to reach the compatibility of molecular level in a typical melt blending operation. For some polymers synthesized from the same monomer, it may be possible to achieve superior compatibility such as HDPE/LDPE, HDPE/LLDPE, atactic-PS/syndiotactic-PS and isotatic-PMMA/syndiotactic-PMMA [24]. Observations of the fracture morphology by scanning electron microscopy (SEM) [25, 26], measurement of the glass transition temperature $\left(T_{\mathrm{g}}\right), T_{\mathrm{m}}$ or crystallization temperature $\left(T_{\mathrm{c}}\right)[13,17,27]$, and the rheological, fluorescence, turbidity, scattering and Roman spectrum methods, all can be used to determine the compatibility of the blends [28, 29].

The incompatible interface of the polymer blends is believed to actually be helpful in cell nucleation due to the low energy barrier from the classic nucleation theory [30, 31]. Therefore, the incompatible interface cannot fully account for the 
poor foamability of some immiscible polymer blends. In this work, we prepared LDPE/HDPE and LDPE/PP blends using a twin-screw extruder. The compatibility of the blends is investigated by using thermal, rheology and polarized optical microscopy (POM). The extrusion foaming behavior of the blends prepared using different compositions is carefully compared. Subcritical $\mathrm{CO}_{2}$ was used as blowing agent given its environmentally friendly and safe properties (under the foaming conditions, the temperature is higher while the pressure is slightly lower than the critical values, $\left.T_{\mathrm{c}}=31.1{ }^{\circ} \mathrm{C}, P_{\mathrm{c}}=7.37 \mathrm{MPa}\right)$. The viscoelastic properties of the blends and the $\mathrm{CO}_{2}$ diffusivity in the blends were also studied for interpreting the foaming characteristics of the two blends.

\section{Experimental}

\subsection{Materials}

The polymer resins used in this work are commercially available products as listed in Table 1. All the PP resins used were isotactic PP with a linear structure. For nucleation, DFNA-0078NT an LDPE-based nucleating masterbatch from the DOW Chemical company is used. A compatibilizer, ethylene-propylene-diene monomer (EPDM) obtained from the Dow Chemical company with a trade name NORDELTM IP 3745P. $\mathrm{CO}_{2}$ (purity: $99.9 \%$, w/w \%) is obtained from Shanghai Chenggong Gases Inc.

Table 1 Polymers used in this work

\begin{tabular}{cccc}
\hline Materials & Brand & Supplier & MI (g/10min) \\
\hline HDPE & DGDA-6944NT & DOW Chemical Co., Ltd & $8.0^{\mathrm{a}}$ \\
LDPE & DFDB-1258NT & DOW Chemical Co., Ltd & $6.5^{\mathrm{a}}$ \\
PP1 & H9018 & Sinopec Langang company & $54^{\mathrm{b}}$ \\
PP2 & M700R & Sinopec Shanghai company & $7.0^{\mathrm{b}}$ \\
\hline
\end{tabular}




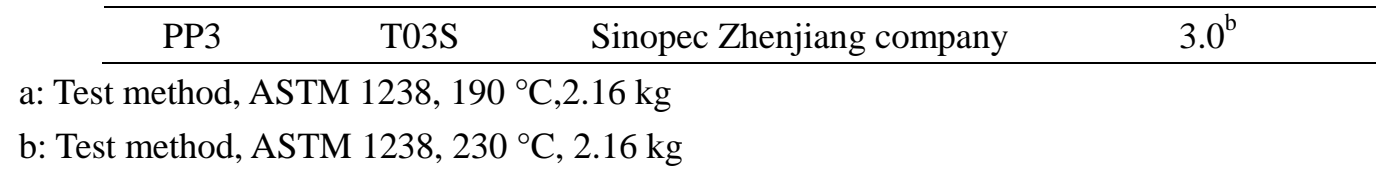

\subsection{Blends preparation}

LDPE/HDPE blends with mass ratios of 100/0, 80/20, 60/40, 40/60, 20/80 and 0/100 were designated as L/H-10/0, L/H-8/2, L/H-6/4, L/H-4/6, L/H-2/8 and L/H-0/10, respectively. LDPE/PP blends with the mass ratio of 90/10, 70/30 and 50/50 were named as $\mathrm{L} / \mathrm{P}-9 / 1, \mathrm{~L} / \mathrm{P}-7 / 3$ and $\mathrm{L} / \mathrm{P}-5 / 5$, respectively. All the samples including the pure HDPE and LDPE coupled with $1.5 \%$ nucleation agents were first dry blended in a high-speed mixer. Melt blending is then conducted on a twin-screw extruder (BM-160M-4). The extruder barrel temperature profile is set at 140-180-190-200-200-200-190 ${ }^{\circ} \mathrm{C}$ from the hopper to the die with as screw speed of $160 \mathrm{rpm}$. The melt extrudate was quenched in water and then cut into pellets using a strand pelletize (TL-115 of Shanghai Tailian Light Industry Machine Making Co. Ltd., China.).

\subsection{Extrusion Foaming of LDPE}

As shown in Fig. 1, a single screw extruder with $50 \mathrm{~mm}$ diameter and $45 \mathrm{~L} / \mathrm{D}$ (Hangzhou Jinghai Plastics Technology Co., China) equipped with a $\mathrm{CO}_{2}$ gas injection system (SFT-10 of Septech Ltd.) is used for the extrusion foaming process. A strand die with an $\mathrm{L} / \mathrm{D}$ ratio of $6 \mathrm{~mm} / 2 \mathrm{~mm}$ is installed at the end of the extruder. Before the foaming step, the pellets were oven-dried at $70{ }^{\circ} \mathrm{C}$ for $10 \mathrm{~h}$. All the trials were maintained at the same conditions: The temperature profile along the extruder is 145-180-200-180-160- $155^{\circ} \mathrm{C}$, the corresponding $\mathrm{CO}_{2}$ weight content 0.8 wt. $\%$ and the screw speed is set at $35 \mathrm{rpm}$. According to previous investigations, more suitable 
foaming die temperatures are $120-140{ }^{\circ} \mathrm{C}$ for LDPE/HDPE blends and $130-150{ }^{\circ} \mathrm{C}$ for LDPE/PP blends $[6,12]$. However, pressure fluctuations were too high and the die would become plugged if the temperature is maintained at $130-140{ }^{\circ} \mathrm{C}$ especially for the L/P-5/5 systems. Therefore, in order to maintain similar foaming conditions, the die temperature is set as $155^{\circ} \mathrm{C}$. The corresponding die pressure is approximate 7 $\mathrm{MPa}$, which is near the $\mathrm{CO}_{2}$ critical pressure. The detailed extrusion foaming procedure is shown elsewhere [32].

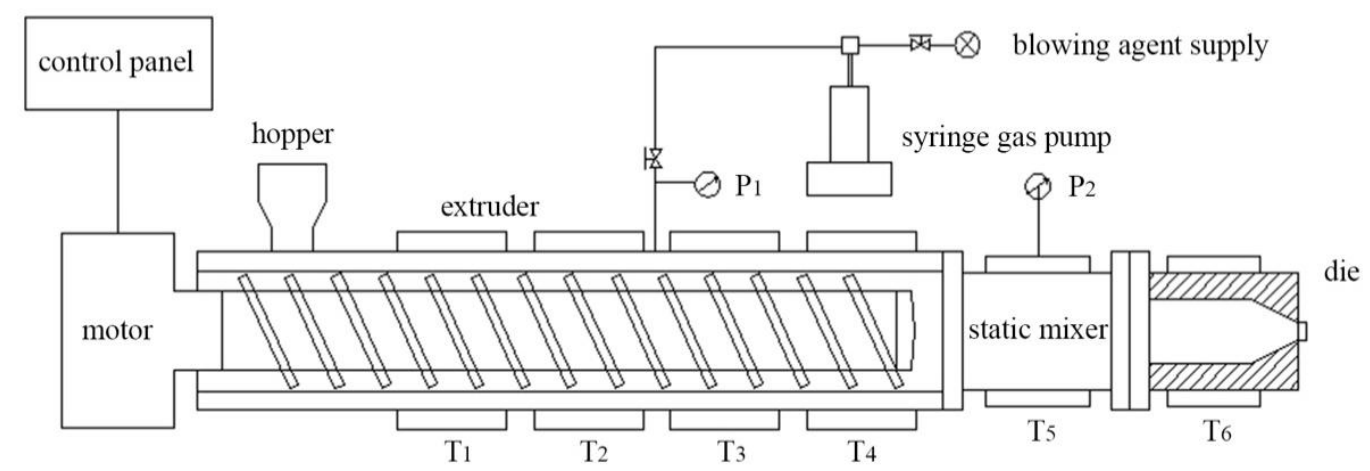

Fig. 1. Experimental extrusion foaming apparatus

\subsection{Characterization}

The melting and crystallization characteristics were evaluated using differential scanning calorimeter (DSC, NETZSCH DSC204 HP) under ambient nitrogen atmosphere. Before the measurements, the blend compounds were dried in a vacuum oven at $70{ }^{\circ} \mathrm{C}$ for $5 \mathrm{~h}$. The samples were heated to $200{ }^{\circ} \mathrm{C}$ from room temperature at a heating rate of $10{ }^{\circ} \mathrm{C}$, held at $200{ }^{\circ} \mathrm{C}$ for $5 \mathrm{~min}$ to eliminate the thermal history, and then cooled at a rate of $2{ }^{\circ} \mathrm{C} / \mathrm{min}$ to $60{ }^{\circ} \mathrm{C}$. Finally, the blends were then heated from $60{ }^{\circ} \mathrm{C}$ to $200{ }^{\circ} \mathrm{C}$ at a rate of $10{ }^{\circ} \mathrm{C} / \mathrm{min}$. The crystallization and melting temperatures were obtained from the cooling and the second-heating thermograms. 
Rheological measurements were performed using a rotational rheometer (TA-ARES instruments) set in dynamic oscillatory mode. A parallel-plate geometry (25 mm diameter) is selected for measurements at small amplitude oscillatory shear under a controlled strain of $5 \%$ within the linear viscoelastic range. The angular frequencies were swept from 100 to $0.05 \mathrm{rad} / \mathrm{s}$ at $180{ }^{\circ} \mathrm{C}$ with $1.6 \mathrm{~mm}$ gap and 10 points were recorded per decade.

POM is carried out using an Olympus microscope equipped with an Olympus DP70. The samples were first heated to $200{ }^{\circ} \mathrm{C}$ and held for 5 min to completely melt the crystallization area, and then cooled to $120^{\circ} \mathrm{C}$ as soon as possible.

The blend morphology and foamed samples were observed using an SEM type JSM-6360LV. The foamed samples were fractured in liquid nitrogen, and then the fracture surface is sputter-coated with Pd (palladium) for SEM observation. The volume expansion ratio, $R_{\mathrm{v}}$, defined as the ratio of the bulk density before and after foaming, is estimated using Eq. (1):

$R_{v}=\rho_{0} / \rho_{f}$

where $\rho_{0}$ and $\rho_{\mathrm{f}}$ are the mass densities before and after foaming; $\rho_{\mathrm{f}}$, is measured according to ASTM D792-00 by weighing a sample of the polymer foam in water using a sinker. The cell density, $N_{0}$, the number of cells per cubic centimeter of solid polymer is determined from Eq.(2):

$N_{0}=\left[\frac{n M^{2}}{A}\right]^{3 / 2} R_{v}$

where $n$ is the number of cells in the SEM micrograph, $M$ is the magnification factor, $A$ is the area of the micrograph $\left(\mathrm{cm}^{2}\right)$, and $R_{\mathrm{v}}$ is the expansion ratio. 
The diffusion coefficient of $\mathrm{CO}_{2}$ in the polymer blends is measured with MSB. First, the samples were heated to $170{ }^{\circ} \mathrm{C}$ to melt the crystalline region, and then the samples were cooled to $130{ }^{\circ} \mathrm{C}$ for the measurement. The one-dimensional diffusion equation of Fick's second law could be derived as below [33],

$\frac{M_{t}}{M_{e q}}=1-\frac{8}{\pi^{2}} \sum_{n=0}^{\infty} \frac{1}{(2 n+1)^{2}} \exp \left[\frac{-(2 n+1)^{2} \pi^{2} D t}{4 L^{2}}\right]$

where $M_{\mathrm{t}}$ and $M_{\mathrm{eq}}$ are the amount of $\mathrm{CO}_{2}$ dissolved in samples at time $t$ and sorption equilibrium under certain stepwise pressure change, respectively. The sample thickness $L$, is calculated from the volume of the sample. The details of this approach can be found elsewhere [34].

\section{Results and discussion}

\subsection{Compatibility of LDPE/HDPE blends}

Since both LDPE and HDPE are synthesized using the same monomer, observation of the fracture by SEM to characterize phase compatibility is difficult. This is primarily due to the fact that finding a solvent to selectively extract one of the phases is nearly impossible. In this work, the compatibility of PE blends is characterized indirectly via thermal and rheology analyses. The $T_{\mathrm{m}}$ and $T_{\mathrm{c}}$ of PE blends were measured to characterize the compatibility. In addition, the shape of the melting and crystallization peaks is closely related to the foaming process. For example, the narrower melting peaks indicate a smaller foaming window since the fast solidification would hinder the cell growth. Fig. 2 (a) and (b) show the melting and cooling curves of LDPE/HDPE blends at different ratios, respectively. It is observed that the melting and crystallization temperatures were reduced with 
increasing LDPE content, and the crystallinity of the blends also decreased since the branched chain of LDPE hindered the crystallization process. When the LDPE content exceeded $60 \mathrm{wt} \%$, the dual $T_{m}$ and $T_{c}$ are visible, but it should also be noted that the second melting and cooling peaks were weak, indicating a low level of incompatibility. In addition, from the integral area of the crystallization peak, it can be seen that the majority of the crystallization is generated during the first crystallization process.
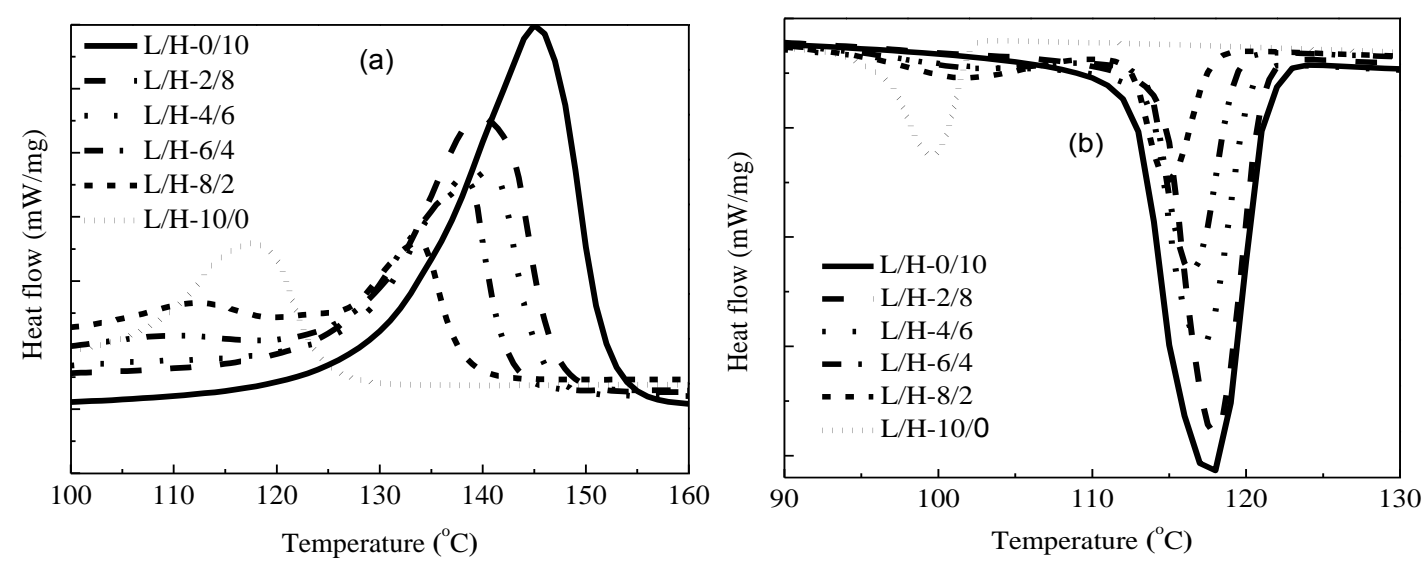

Fig. 2. DSC traces of the melting (a) and crystallization (b) transitions of LDPE/HDPE blends

The DSC analysis is based on the heat flow of the sample without shear or extension flow. While the foaming processes especially the continuous extrusion foaming are performed under substantial shear and extension. Thus, the rheology analysis is a suitable supplement to understand phase compatibility under the effect of a flow field. Dynamic oscillatory sweep frequency test data are generally presented in the form of Cole-Cole plots, van Gurp-Palmen plot, zero-shear viscosity as a function of concentration and relaxation spectrum, and are used to analyze the compatibility of polymer blends [35-37]. Fig. 3 shows the Cole-Cole plots of the LDPE/HDPE blends. It is observed that the semicircular shape is evident for all the blends without any 
trends of rising in the terminal. Moreover, the radius of the semicircular increased with increasing the LDPE content, implying that the blends were compatible.

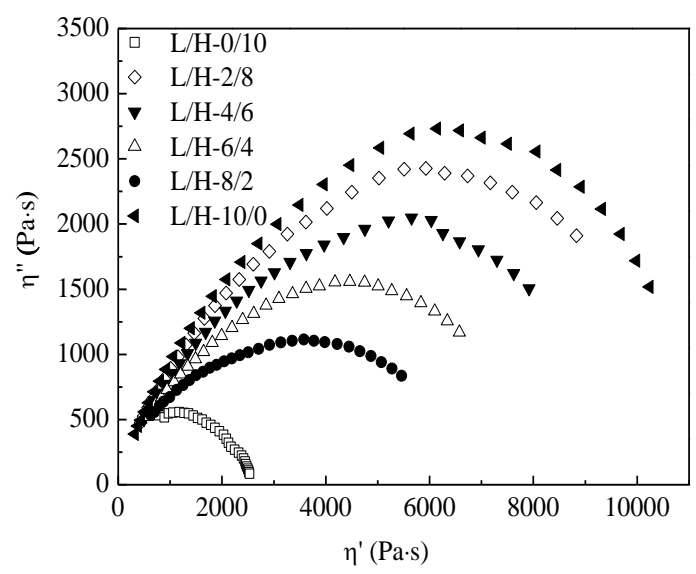

Fig. 3. Cole-Cole plots of HDPE/LDPE blends at $180{ }^{\circ} \mathrm{C}$

The weighted relaxation spectra $(\lambda H(\lambda))$ is also constructed to extract further information about the compatibility of the blends. The continuous relaxation spectrum, $H(\lambda)$ can be obtained by fitting $G$ ' and $G$ ' data using the standard nonlinear regression method based on the model developed by Ninomiya and Ferry as below [38].

$$
\begin{aligned}
& G^{\prime}=\int_{-\infty}^{\infty} H(\lambda) \frac{\omega^{2} \lambda^{2}}{1+\omega^{2} \lambda^{2}} d \ln \lambda \\
& G^{\prime \prime}=\int_{-\infty}^{\infty} H(\lambda) \frac{\omega \lambda}{1+\omega^{2} \lambda^{2}} d \ln \lambda
\end{aligned}
$$

The weighted relaxation time spectrum is shown in Fig. 4. The pure HDPE, LDPE and their blends all presented single characteristic relaxation time. The LDPE exhibited a longer characteristic relaxation time compared to HDPE due to its branch structure which impeded the chain segments relaxation. The single characteristic relaxation time of the LDPE/HDPE blends is also as large as that of LDPE, indicating that the branched chains had intertwined together. Thus, the LDPE/HDPE blends could be assumed compatible based on the weighted relaxation time spectra. 


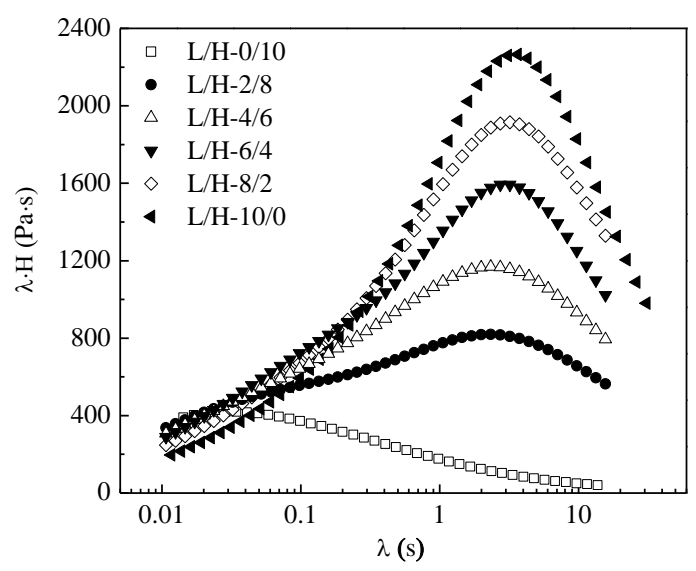

Fig. 4. Weighted relaxation time spectra of LDPE/HDPE blends

It could be concluded from both the DSC and the rheology results that the LDPE/HDPE blends were highly compatible at LDPE content of less than $60 \mathrm{wt} \%$. When the LDPE content exceeded $60 \mathrm{wt} \%$, the DSC results are inconsistent with that of the rheology analysis. Datta et al. [39] have assumed that the higher LDPE content introduced more branches which excluded the polyethylene unit cell from forming thinner lamellae. Thus, it appeared that dual melting and crystallization peaks from the aspects of thermal dynamics. However, it is known that the shear stresses imposed by an external flow field could lead to deformation and break-up of the dispersed domains, which enhances blend dispersion and distribution. On the basis of the analysis on their thermal properties and rheology analysis, it could be concluded that the LDPE/HDPE blends exhibited a high level of compatibility.

\subsection{Compatibility of LDPE/PP blends}

Although the PE and PP have similar structures and both are non-polar polymers, they present a typical incompatible phase structure $[12,26]$. The thermal properties of LDPE/PP blends are listed in Table 2. All the blends exhibited dual $T_{\mathrm{m}}$ and $T_{\mathrm{c}}$. The higher one corresponded to the PP phase, and the lower to the LDPE. Both of them 
were close to those of the pure polymer. Compared with the LDPE/HDPE blends, the LDPE/PP blends would undergo two melt-solidification processes: one corresponding to PP crystallization, and the other to LDPE.

Table 2 Melting and crystalline temperature of the LDPE/PP blend

\begin{tabular}{crrrrc}
\hline Sample & Ratio & $T_{\mathrm{m} 1}\left({ }^{\circ} \mathrm{C}\right)$ & $T_{\mathrm{m} 2}\left({ }^{\circ} \mathrm{C}\right)$ & $T_{\mathrm{c} 1}\left({ }^{\circ} \mathrm{C}\right)$ & $T_{\mathrm{c} 2}\left({ }^{\circ} \mathrm{C}\right)$ \\
\hline \multirow{4}{*}{ LDPE/PP1 } & $9 / 1$ & 167.6 & 117.6 & 138.7 & 101.7 \\
& $7 / 3$ & 168.7 & 115.7 & 139.8 & 101.8 \\
& $5 / 5$ & 169.8 & 115.4 & 138.7 & 101.8 \\
\cline { 2 - 6 } LDPE/PP2 & $9 / 1$ & 167.8 & 117.3 & 120.2 & 100.6 \\
& $7 / 3$ & 168.4 & 115.1 & 121.0 & 101.4 \\
& $5 / 5$ & 169.0 & 115.0 & 122.1 & 101.7 \\
\cline { 2 - 6 } LDPE/PP3 & $9 / 1$ & 167.3 & 117.8 & 121.0 & 100.7 \\
& $7 / 3$ & 168.7 & 115.5 & 121.1 & 101.4 \\
& $5 / 5$ & 169.4 & 115.2 & 123.1 & 101.0 \\
\hline
\end{tabular}

Jordhamo et al. have confirmed that the viscosity and composition both affect the phase structure [40]. In this work, PP resins having different MI were utilized as blend components with LDPE to qualitatively investigate the effect of the component viscosity on the blends phase structure. Considering that the LDPE and PP have very similar solubility parameters and the LDPE is the dominant phase, selecting a suitable solvent to etch the PP phase is difficult. Fortunately, the difference in $T_{\mathrm{c}}$ between PP and LDPE is higher than $20{ }^{\circ} \mathrm{C}$. Thus, it is a suitable method for determining the compatibility of LDPE/PP blends if the crystallization temperature of the blends is between the $T_{\mathrm{cPP}}$ and $T_{\mathrm{cLDPE}}$.

Fig. 5 shows the typical optical images of the microstructure of the blends. For the mass composition of $9 / 1$, the blends exhibited the typical sea-island, or matrix-dispersed phase structure, and the size of the PP dispersed phase decreased with increasing MI of the PP phase. This is due to a change in the competing shear 
stress exerted by the matrix in comparison to weaker dispersed phase as PP MI is increased. For the composition of 7/3, LDPE/PP1 and LDPE/PP2 blends maintained the sea-island structure, while LDPE/PP3 showed the PP phase forming a lamellar/lace structure in the process of being stretched and broken up by the matrix; and could be leading to an onset of a co-continuous morphology. For the composition of $5 / 5$, the sea-island structure with larger size of the dispersed phase is maintained in the LDPE/PP1 blend. However, the LDPE/PP2 and LDPE/PP3 blends show microstructures which could best described as co-continuous. Comparing the phase structures of the three LDPE/PP blends, the results clearly show that the blends phase structure is closely related to the components viscosity as well as the blend composition. A low level of a lower viscosity PP is conducive to the formation of a distinct dispersed phase in the PE matrix, while co-continuous structures have tendency to appear at a higher content of PP with low MI.
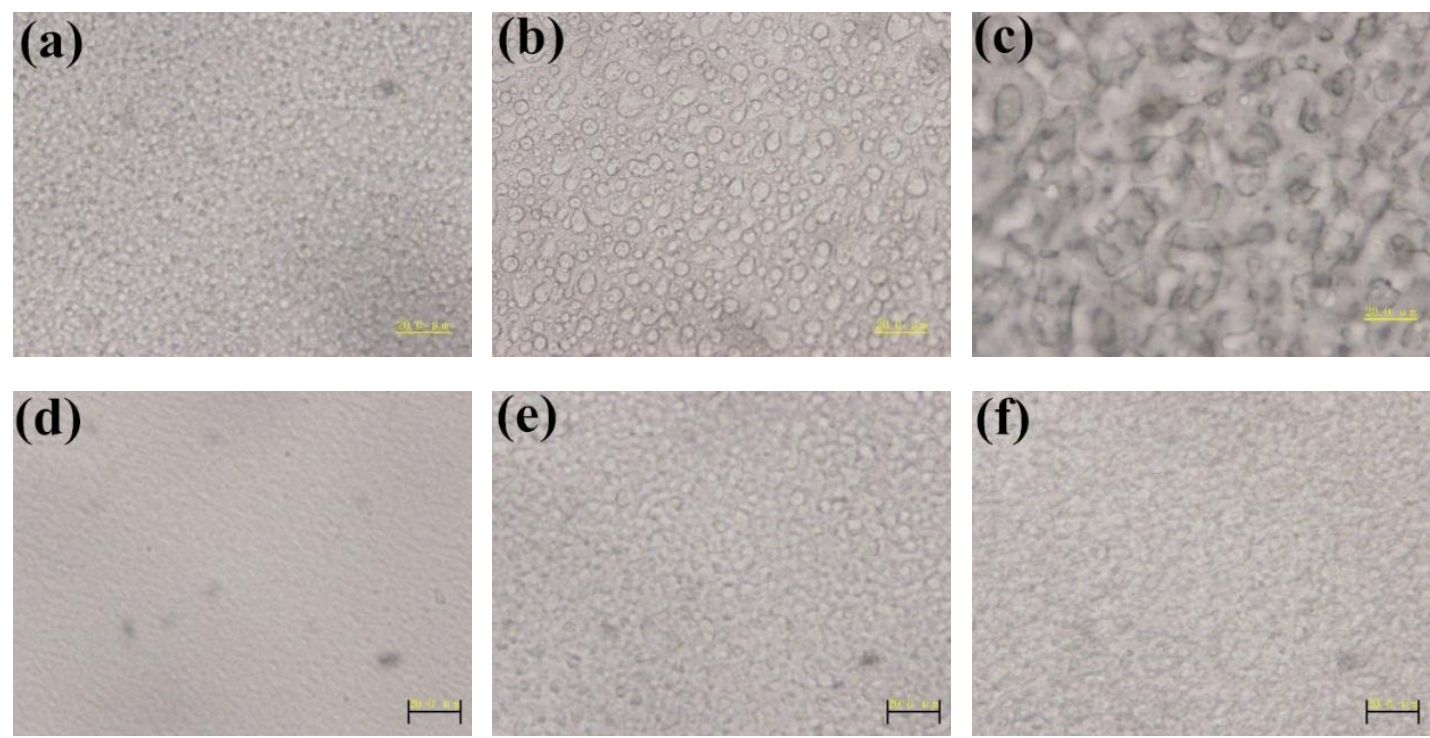

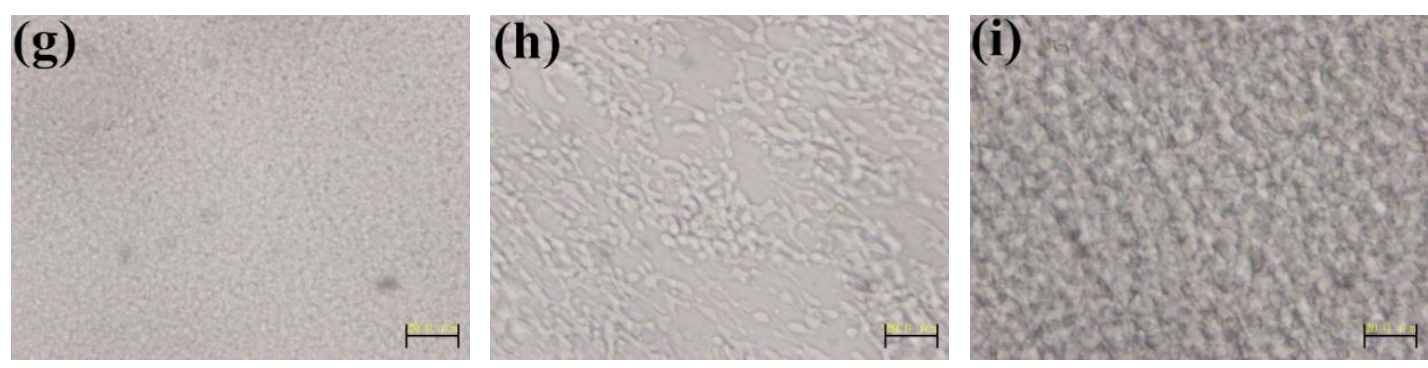

Fig. 5. POM images for polymer blends: (a) LDPE/PP1-9/1; (b) LDPE/PP1-7/3; (c) LDPE/PP1-5/5; (d) LDPE/PP2-9/1; (e) LDPE/PP2-7/3; (f) LDPE/PP2-5/5; (g) LDPE/PP3-9/1; (h) LDPE/PP3-7/3; (i) LDPE/PP3-5/5.

\subsection{Foaming behaviors of LDPE/HDPE and LDPE/PP blends}

\subsubsection{Die-swell of blends extrudate}

The cell morphology of polymer foams is affected primarily by the cell nucleation, cell growth and cell coalescence during the foaming process. Cell nucleation is critical to the foaming process since it determines the bubble density, i.e. number of cells per unit volume of foamed polymer. In order to contrast the foaming results of the LDPE/HDPE and LDPE/PP blends, all the processing conditions were keep constant including the screw speed, die set temperature, $\mathrm{CO}_{2}$ content and nucleation agent content, which had a significant effect on the foaming results. Fig. 6 shows a typical image of the blend extrudate. The initial expansion angle $(\theta)$ is obtained from the image as shown in the figure. During polymer extrusion in the absence of foaming, the die-swell is closely related to the viscoelastic properties of the polymer, especially the storage modulus [41]. During extrusion foaming, cell nucleation should not be ignored $[8,42]$. The relationship between the initial angle and cell nucleation could be interpreted as follows: the nucleated cell could be considered as the initial formation of the final bubble, and the higher initial angle is an indication that a larger number of newly formed bubbles is obtained following the significant pressure drop experienced 
as the material is pushed across the die. Comparing the two images in Fig. 6, it is obvious that the LDPE/PP blend extrudate possesed a higher initial angle compared to the LDPE/HDPE blend under the same extrusion conditions. In addition, a transparent region can be seen in the LDPE/HDPE blends exiting the die, which indicative of delayed initiation of foaming compared to their LDPE/PP conterpart. In order to determine which effect dominates the die-swell of the extrudate, the cell nucleation or the storage modulus, the storage modulus was measured under the same processing conditions and Fig. 7 shows the $G^{\prime}$ of the two blends. The $G^{\prime}$ did not show a significant difference since it mainly depends on the branched chain of LDPE. Therefore, it can be concluded that the LDPE/PP blends show a better cell nucleation, which could be attributed to the phase incompatibility of the blends. The morphology of the LDPE/PP blends appears to contribute significantly to cell nucleation.

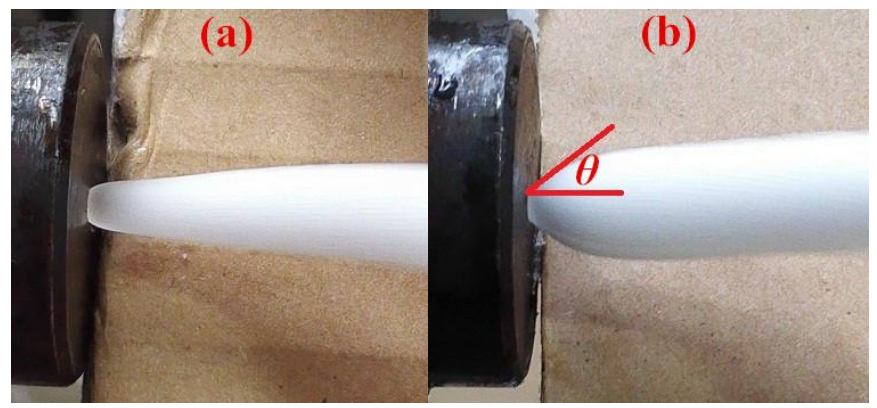

Fig. 6. A typical image of LDPE/HDPE (a) and LDPE/PP (b) blends foaming extrudate
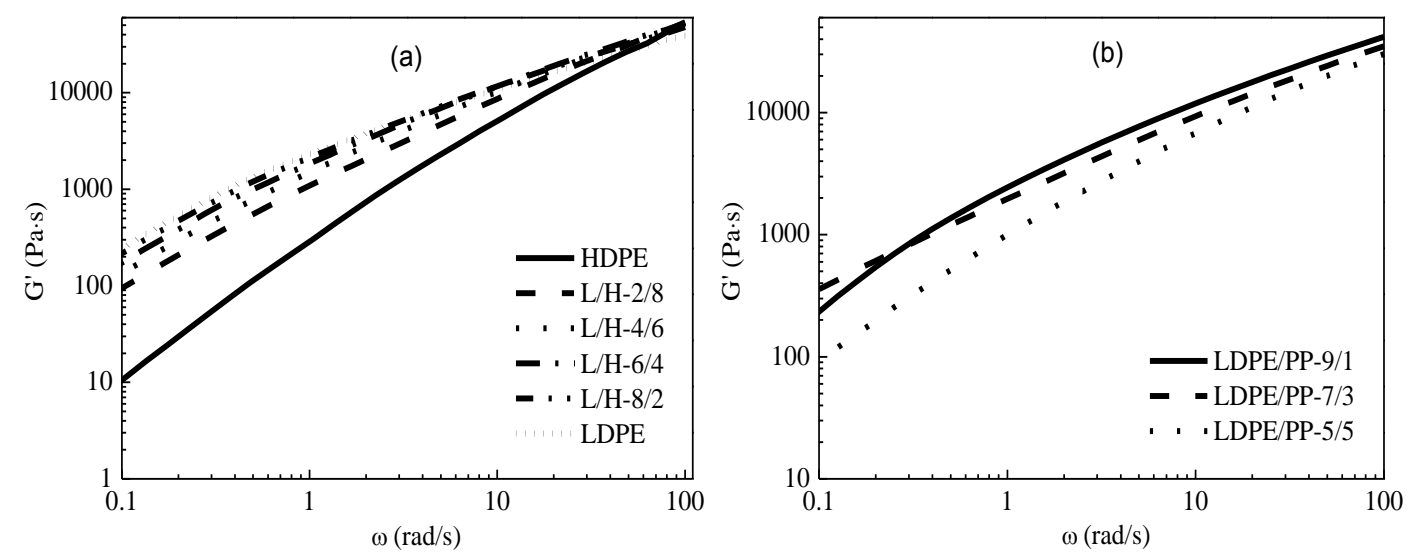
Fig. 7. Storage modulus of LDPE/HDPE blends (a) and LDPE/PP1 blends (b), all measurements under $5 \%$ strain and $180{ }^{\circ} \mathrm{C}$ temperature.

\subsubsection{Extrusion foaming of LDPE/HDPE blends}

Fig. 8 shows SEM images of the cell morphology for foams made from the LDPE/HDPE blends at different composition. Due to its linear structure, HDPE has a low melt strength and as shown, could not sustain cell growth, thus resulting in severe cell collapse (Fig. 8 (a)). All the other LDPE/HDPE compostions resulted in a structured cell morphology. Table 3 shows the cell densities and mean cell size of the LDPE/HDPE blend foams with different composition. For $\mathrm{L} / \mathrm{H}-0 / 10$, the low melt strength, pure HDPE could not resist gas expansion during cell growth, thus resulting in large, collapsed cells. With a 20\% LDPE content, the high melt strength of the LDPE phase with branched chains is clearly beneficial to the foaming process, which has been confirmed by a number of researchers $[7,8,43]$. The expansion ratio, cell density and cell size all showed a clear improvement. However, as LDPE content continued to increase, the foaming results don't show significant additional improvement. This can be attributed to the relatively lower gas content, die pressure, depressurization rate and higher die temperature. If the preferential condition was chosen, the more LDPE should be beneficial to the foaming results.
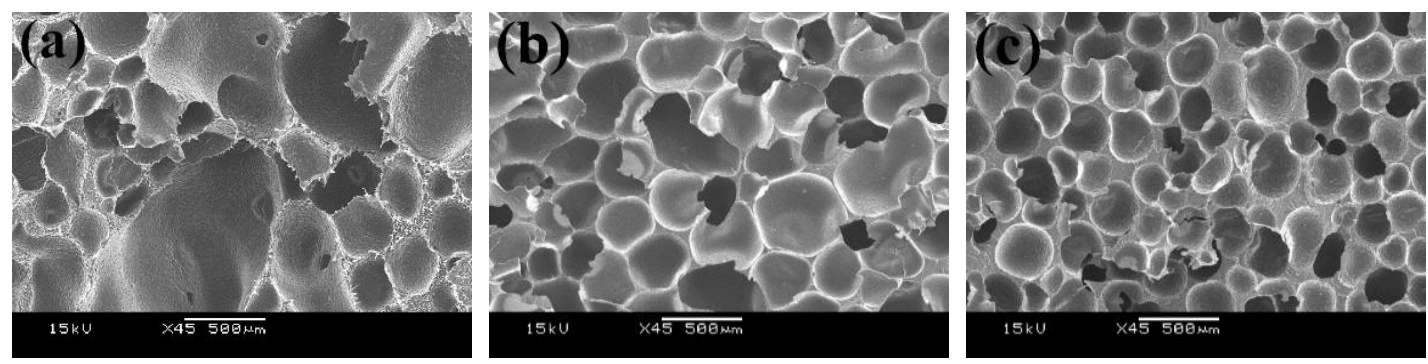

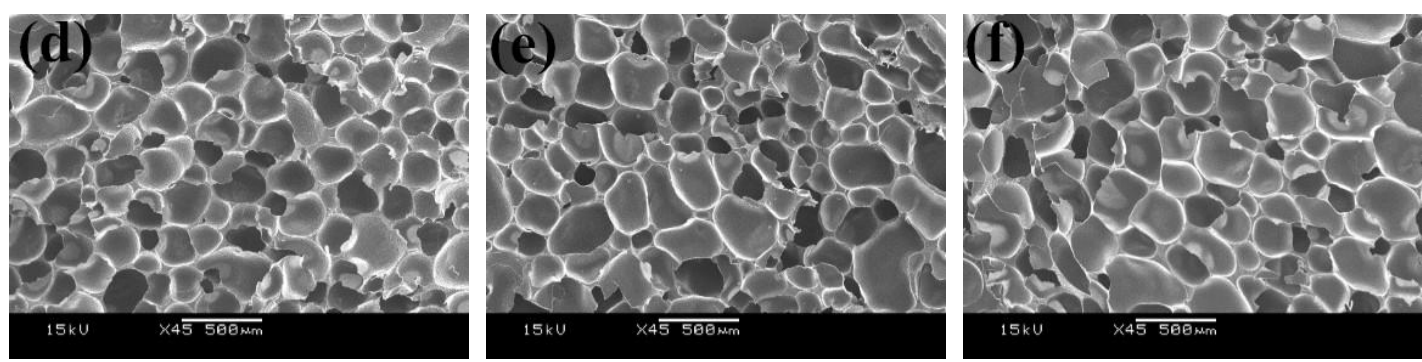

Fig. 8. SEM images of the cell morphology, (a) L/H-0/10; (b) L/H-2/8; (c) L/H-4/6; (d) L/H-6/4; (e) $\mathrm{L} / \mathrm{H}-8 / 2$; (f) $\mathrm{L} / \mathrm{H}-10 / 0$.

Table 3 Initial foam expansion angle, expansion ratio, cell density and mean cell diameter: LDPE/LDPE blends.

\begin{tabular}{ccccc}
\hline Sample & $\begin{array}{c}\text { Initial expansion } \\
\text { angle }\left({ }^{\circ}\right)\end{array}$ & $\begin{array}{c}\text { Expansion } \\
\text { ratio }\end{array}$ & $\begin{array}{c}\text { Cell density } \\
\left(10^{5} \text { cells } / \mathrm{cm}^{3}\right)\end{array}$ & $\begin{array}{c}\text { Mean cell } \\
\text { diameter }(\mu \mathrm{m})\end{array}$ \\
\hline $\mathrm{L} / \mathrm{H}-0 / 10$ & $/$ & 1.6 & $/$ & $/$ \\
$\mathrm{L} / \mathrm{H}-2 / 8$ & 8 & $4.5 \pm 0.1$ & $0.75 \pm 0.05$ & 335 \\
$\mathrm{~L} / \mathrm{H}-4 / 6$ & $13 \pm 2$ & $5.0 \pm 0.2$ & $1.05 \pm 0.08$ & 315 \\
$\mathrm{~L} / \mathrm{H}-6 / 4$ & $15 \pm 3$ & $5.3 \pm 0.2$ & $1.17 \pm 0.11$ & 290 \\
$\mathrm{~L} / \mathrm{H}-8 / 2$ & $10 \pm 3$ & $4.9 \pm 0.2$ & $1.13 \pm 0.13$ & 295 \\
$\mathrm{~L} / \mathrm{H}-10 / 0$ & $10 \pm 3$ & $5.0 \pm 0.2$ & $1.10 \pm 0.12$ & 296 \\
\hline
\end{tabular}

\subsubsection{Extrusion foaming of LDPE/PP blends}

Fig. 9 shows cell images of foam samples made from the LDPE/PP blends. The details of the foaming results are shown in Table 4. For the three LDPE/PP blends, and regardless of the composition, they all exhibited a high die-swell. The data show that the cell size decreased from $450 \mu \mathrm{m}$ to $300 \mu \mathrm{m}$ as the MI of the PP component decreased from 54 to 3 . For the compositions $9 / 1$ and 7/3, the PP component does not appear to have any obvious effect on the foaming behavior since LDPE is the dominate phase. However, there is a clear indication of the bubbles wall becoming thinner and eventually resulting in cell break up and combination leading to overall larger bubbles. For example, the 5/5 LDPE/PP1 composition resulted in severe bubble collapse and could not sustain the formation of a closed cell strucuture. For the LDPE/PP2 and LDPE/PP3, the cell size decreased slightly with compositions $9 / 1$ and 7/3 while decreasing remarkedly with composition $5 / 5$ probably driven by faster 
solidification of the PP phase, thus constraining cell growth. In addition, the smaller expansion ratio is due to the severe melt collapse during the cell growth stage.

In comparison to the foaming behavior of LDPE/HDPE blends, the impact of the PP phase in LDPE/PP blends had a significant impact on the foaming results, quite different from the impact of HDPE in the LDPE/HDPE blends. The initial expansion angle incresed from approximately $10^{\circ}$ to $43^{\circ}$ compared to LDPE/HDPE blends. However, only the 9/1 and 7/3 LDPE/PP blend compositions exhibiting a dispersed phase morphology (sea-island), showed a similar expansion ratio and a structure with a larger cell size. The 5/5 blend compositions with a co-continuous phase structure showed a poor foaming performance despite intially higher cell nucleation. By contrast to the LDPE/HDPE blends, which all were able to maintain a good foaming performance regardless of their composition, the LDPE/PP with a 5/5 composition could not sustain foaming. To best understand the problem, three PP resins having different MI were chosen to blend with LDPE. The results show that when the LDPE is the dominant phase, the foaming behavior is similar to the LDPE/HDPE system. However, at equal content of LDPE and PP, the foaming behavior was different and dependent on the type of the PP resin used. It can therefore be concluded, that other factors exist that influenced the foaming behavior of these two different blend systems. Considering that the LDPE/PP blends had resulted to a better onset of foaming at the die exit, the latter poor foaming performance could be mainly attributed to melt collapse during the cell growth stage.

Table 4. Initial foam expansion angle, expansion ratio, cell density and cell diameter: LDPE/PP blends 


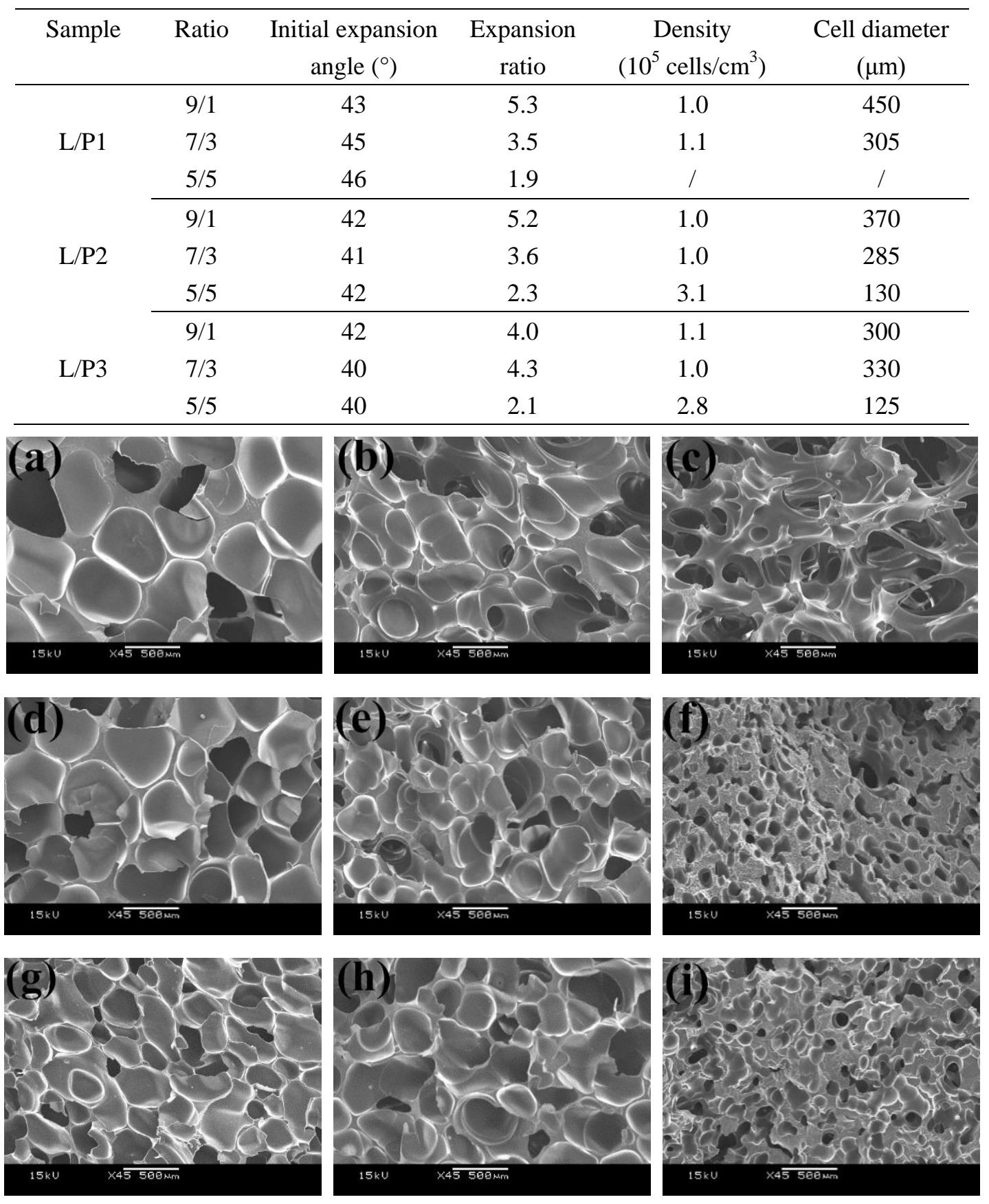

Fig. 9. SEM images of the cell morphology, (a) LDPE/PP1-9/1, (b) LDPE/PP1-7/3, (c) LDPE/PP1-5/5; (d) LDPE/PP2-9/1, (e) LDPE/PP2-7/3, (f) LDPE/PP2-5/5; (g) LDPE/PP3-9/1, (h) LDPE/PP3-7/3, (i) LDPE/PP3-5/5;

\subsubsection{Effect of rheology on the foaming behavior of LDPE/PP blends}

The foaming behavior is closely related to the rheology including viscosity and storage modulus. Fig. 10 shows the complex viscosity profiles for LDPE/HDPE and LDPE/PP blends at different compositions. The complex viscosity at low shear rate is an indication of the melt strength also as indicated by the storage modulus from Fig. 7. 
The complex viscosity of pure HDPE and PP1 resins are lower than those of the blends and both exhibited a plateau in the low frequency region. The addition of LDPE had a noticeable influence on the rheology hehavior of the blends. Both the low shear viscosity as well as the shear-shinning behavior increased siginificantly, which is linked to the long-chain branch structure of LDPE. For the PP2 and PP3 resins, the complex viscosity profile showed a higher viscosity when compared to those of pure HDPE or PP1 as well as their blends. The shear-shinning behavior is seen to increase as LDPE is added in the LDPE/PP2 blends, while the same is not true for the LDPE/PP3 blends. It should be noted that the addition of LDPE in the LDPE/PP1 blends had a significant impact on changing the rheology profile of the blends. For example the low shear viscosity as well as the shear thinning behavior of the LDPE/PP1 blends were changed to an extent such that they became quite comaprable to the LDPE/HDPE system. Therefore, regardless of the composition, the poor foaming behavior of the LDPE/PP blends can not be attributed solely to the melt strength and branch content since all the blends were modified with similar levels of the branched LDPE.
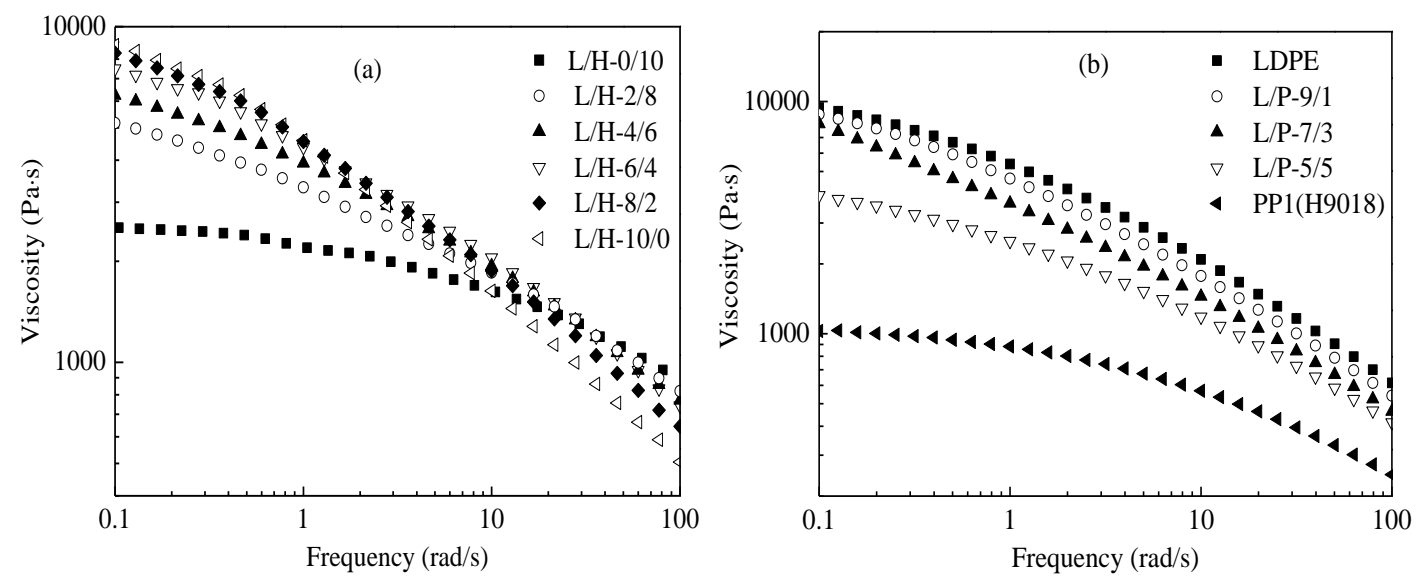

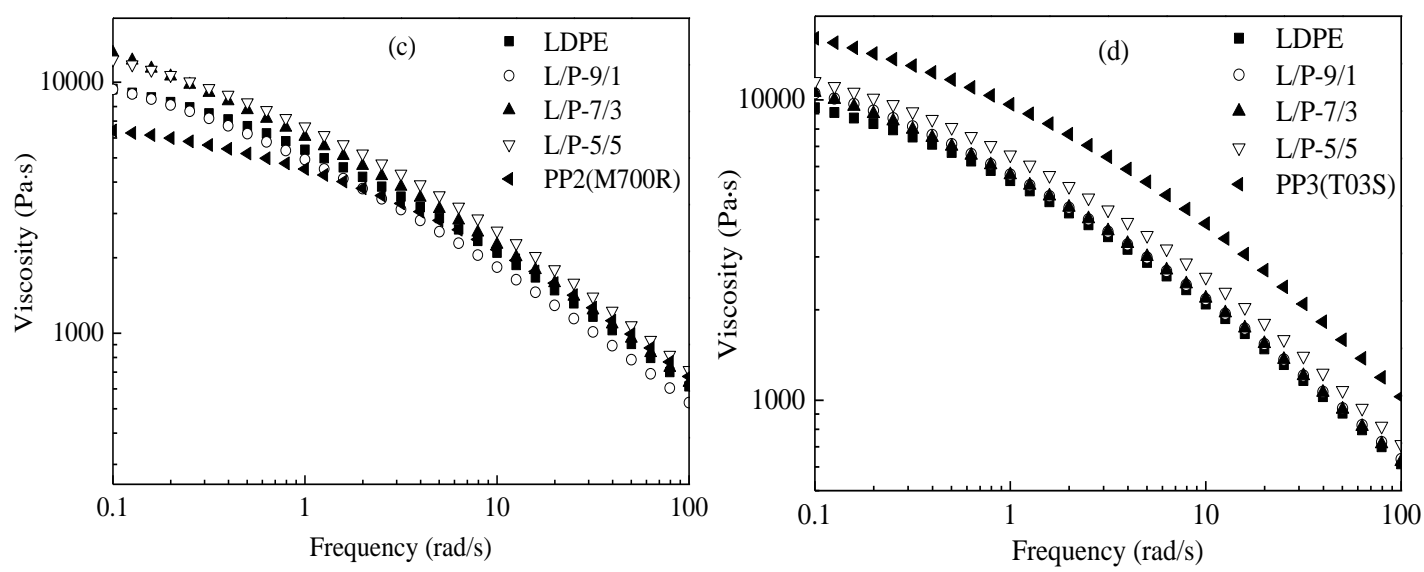

Fig.10. Complex viscosity presented as a function of frequency at $180{ }^{\circ} \mathrm{C}$ for (a) LDPE/HDPE, (b) LDPE/PP1, (c) LDPE/PP2 and (d) LDPE/PP3

\subsubsection{Effect of $\mathrm{CO}_{2}$ diffusion on the foaming behavior of LDPE/PP blends}

As previously indicated, the LDPE/PP blends exhibited earlier foam initiation as shown by the extent of swelling at the die exit. However, this was followed by subsequent foam collapse. It is known that extent of foaming as measured by the expansion ratio is affected by the melt strength, gas solubility, and diffusion of the foaming agent amongst others. The rheology data discussed earlier do not support the hypothesis of the melt strength being the primary driver for the foaming performance observed with the LDPE/PP blends. For this reason, it is important to examine the phase structure of the blends as another property that can potentially influence gas diffusion and thus foaming. MSB is used to measure the solubility and diffusion coefficient of $\mathrm{CO}_{2}$ in the blends under conditions ranging from subcritical to supercritical and the results are shown in Fig. 11. The polymer samples were first heated to $170{ }^{\circ} \mathrm{C}$ for complete melting, and then cooled to $130{ }^{\circ} \mathrm{C}$ which is closer to the foaming temperature in the foaming process used. For this analysis, only the LDPE/HDPE blend with the ratio of $6 / 4$ was selected for comparison with the LDPE/PP blends since the LDPE/HDPE blends did not show a significant difference 
in gas solubility and diffusivity. On the other hand, the solubility and diffusivity of LDPE/PP2 blends was selected for comparison.
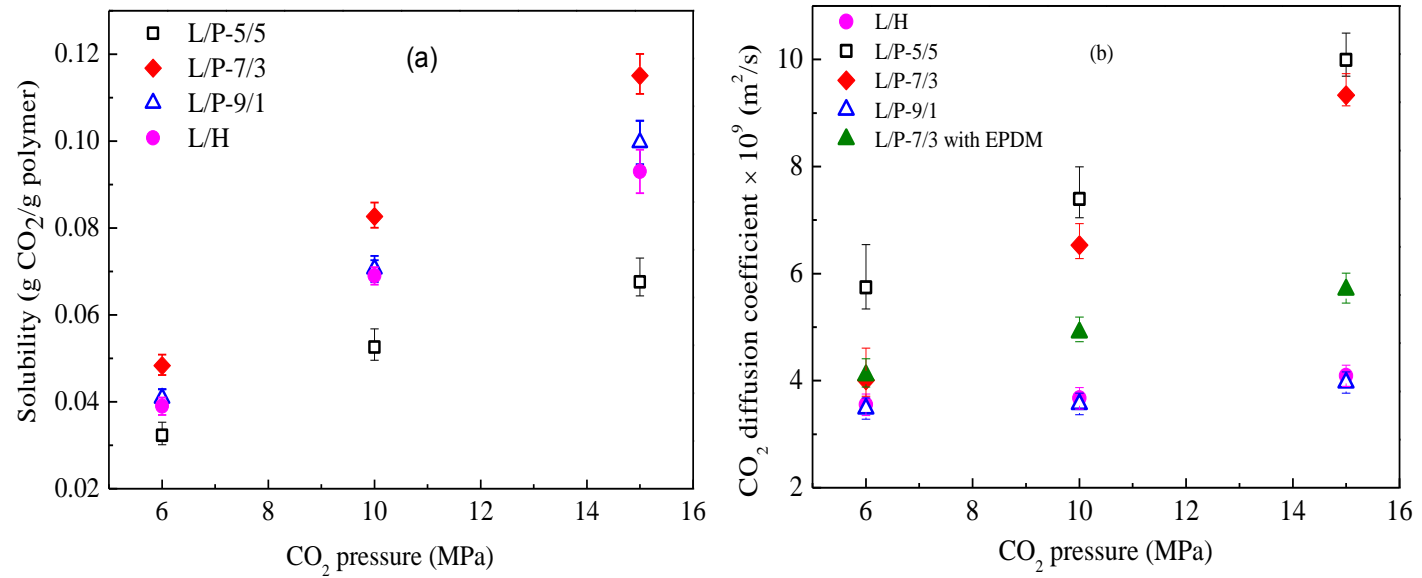

Fig. 11. Solubility (a) and Diffusion Coefficients (b) of LDPE/HDPE, LDPE/PP2 Blends LDPE/PP2/EPDM at $130{ }^{\circ} \mathrm{C}$

As shown in Fig. 11, the solubility was found to initially increase and then decrease as the PP content was increased. While the $\mathrm{CO}_{2}$ diffusion coefficient increased linearly as the PP content was increased. For comparison, a compatibilizer, EPDM was added to the LDPE/PP blends at a weight ratio of $1 \%$. It was found that the gas diffusivity of L/P in the presence of EPDM was between the L/P-7/3 (and/or $\mathrm{L} / \mathrm{P}-5 / 5$ ) and $\mathrm{L} / \mathrm{P}-9 / 1$ (and/or $\mathrm{L} / \mathrm{H}$ ), indicating that the compatibilizer as usually understood to interact at the interface to improve the compatibility of dissimilar phase, had an effect on the interface channels resulting in a reduction in gas diffusion. At the test temperature of $130{ }^{\circ} \mathrm{C}$, the PP phase would begin to solidify and exhaust the dissolved gas. In the meantime, the LDPE phase would maintain its molten state. The soft, molten LDPE and the hard, solid PP would lead to the formation of an interface which would hold gas so as to increase the solubility. Thus, increasing the amount of PP would increase channel formation for gas reserve. On the other hand, PP solidification would lead to decreased gas dissolution, thus the initial increase in gas 
solubility and then the decrease as the PP content is increased. With regard to the diffusion coefficient, the formation of the interface channels due to the PP solidification is also expected to facilitate gas escape.

Fig. 12 shows a schematic for the proposed diffusion mechanism of $\mathrm{CO}_{2}$ in the LDPE/HDPE and LDPE/PP blends. For the compatible LDPE/HDPE blends as shown in Fig. 12 (a), the long-chain branched LDPE has a high miscibility with the HDPE. The blends can be assumed to form a highly homogeneous system as they exhibited uniform physical and chemical properties such as solubility, diffusivity and thermal properties. Furthermore, their rheological properties including a high storage modulus, long relaxation time and high zero-shear viscosity were conducive to better foaming. On the other hand, the incompatible LDPE/PP blends showed typical morphologies of an immiscible blend ranging from fully dispersed (sea-island) to co-continuous phase structures. As shown in Fig. 12 (b), for the blends with a sea-island phase structure, the large amount of LDPE fully engulfed the PP dispersed domains. The dispersed PP domains in the blend systems can play the role of a nucleation agent. For this reason, during initial cell formation, earlier onset of foaming was observed. During subsequent cell growth, the LDPE/PP blends with dispersed PP domains resulted in large bubbles due to overall reduction in melt strength amongst others. For the blends with a co-continuous phase structure, as shown in Fig. 12 (c), due to poor interfacial adhesion, the incompatible components probably resulted in interfacial channel formation leading to potentially rapid gas diffusion from the polymer melt to the surrounding environment. Therefore, the amount of gas held in the blend LDPE/PP 
melt blends necessary for the bubble growth in the co-continuous structures may be lower than in the case of blends with a sea-island or fully miscible systems. Moreover, the blend also showed dual melting and crystallization peaks. As the early solidifying phase becomes unfoamable, both the expansion ratio as well as the bubble size would be smaller.
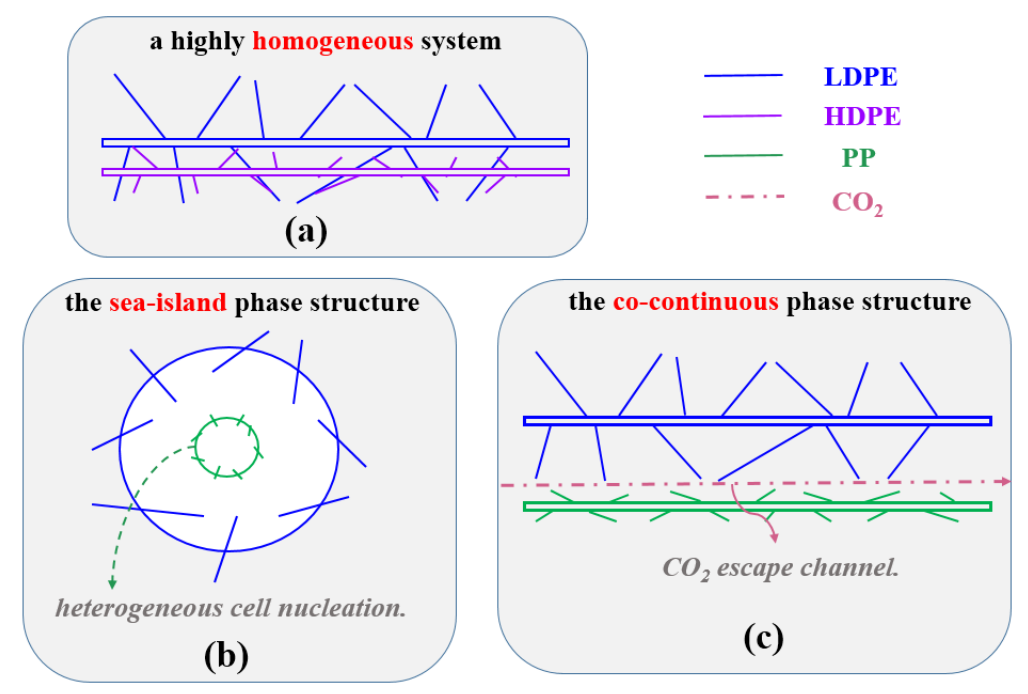

Fig. 12. Schematic diagram of the diffusion mechanism of the polymer blends:

(a) LDPE/HDPE phase structure; (b) the sea-island LDPE/PP phase structure; (c) the co-continuous LDPE/PP phase structure

\section{Conclusion}

This work aimed at investigating the effect of phase compatibility on extrusion foaming of LDPE blends with HDPE and PP. First, the compatibility of LDPE/HDPE blends was characterized via thermal analysis and rheology methods. For this system, the DSC traces showed single melting and crystallization peaks. At high LDPE content exceeding $60 \%$ by weight, only a faint peak close to that of the pure LDPE was observed. The Cole-Cole plots and the weighted relaxation spectrum pointed to good compatibility following shear-induced mixing process used in the blend preparation. For LDPE/PP blends, the system incompatibility has been widely 
acknowledged in previous work. The distribution of PP phase in the blend was observed using POM. At low PP content, the blend resulted in a sea-island structure, which transitioned into a co-continuous structure as the level of PP was increase, especially the lower MI case.

Extrusion foaming of the blends was conducted in a single extruder with gas injection. Regardless of the composition, the compatible LDPE/HDPE blends generated a uniform cell morphology with cell size of about $300 \mu \mathrm{m}$ and expansion ratio of about 5. For the LDPE/PP blends, the incompatible interface was found to be of benefit for the cell nucleation as seen from the expansion angle; however such blends were not able to sustain adequate foaming due to potential gas loss, especially in the case of a co-continuous structure. In the case of a sea-island structure, the expansion ratio was higher and resulted in larger bubbles as well. For the co-continuous structure, both the cell size as well as the expansion ratio was smaller. In order to identify the mechanism behind the difference in the foaming behavior of LDPE/HDPE and LDPE/PP blends, the viscoelastic properties and diffusion coefficients of $\mathrm{CO}_{2}$ in the blends were accurately measured via rheometric and MSB measurements. The results indicated that both the modulus and the viscosity of the blends showed no significant differences. However, the solubility of the blends was shown to first increase then undergo severe reduction, probably due to the solidification of the PP phase, and this became more pronounced with increased PP content. The $\mathrm{CO}_{2}$ diffusion coefficient in the co-continuous structure was found to be higher than in the case of the compatible blends. It can therefore be concluded that the 
viscoelastic properties are not the primary driving factor affecting the foaming behavior of these immiscible blends. The poor foaming performance could possibly be linked to interfacial incompatibility. This is, especially more pronounced in the case of co-continuous phase structures where the interface is larger, thus leading to increased passage for interfacial gas escape.

\section{ACKNOWLEDGMENTS}

The authors are grateful to the National Science Foundation of China (21376087), Research Fund for the Doctoral Program of Higher Education of China (20130074110013), the 111 Project (B08021) and the Fundamental Research Funds for the Central Universities.

\section{Reference}

[1] D.F. Baldwin, C.B. Park, N.P. Suh, An extrusion system for the processing of microcellular polymer sheets: Shaping and cell growth control, Polymer Engineering \& Science, 36 (1996) 1425-1435.

[2] C. Forest, P. Chaumont, P. Cassagnau, B. Swoboda, P. Sonntag, Polymer nano-foams for insulating applications prepared from CO 2 foaming, Progress in Polymer Science, 41 (2015) 122-145.

[3] D.L. Tomasko, A. Burley, L. Feng, S.-K. Yeh, K. Miyazono, S. Nirmal-Kumar, I. Kusaka, K. Koelling, Development of CO2 for polymer foam applications, The Journal of Supercritical Fluids, 47 (2009) 493-499.

[4] A. Maani, H.E. Naguib, M.-C. Heuzey, P.J. Carreau, Foaming behavior of microcellular thermoplastic olefin blends, Journal of Cellular Plastics, 49 (2013) 223-244.

[5] C. Vasile, Handbook of polyolefins, CRC Press, 2000.

[6] N.E. Malwitz, N.S. Ramesh, S.-T. Lee, Closed cell; blend of low density polyethylene and irradiated linear low density polyethylene, in, Google Patents, 2004.

[7] G. Nam, J. Yoo, J. Lee, Effect of long - chain branches of polypropylene on rheological properties and foam - extrusion performances, Journal of Applied Polymer Science, 96 (2005) 1793-1800.

[8] S. Li, M. Xiao, Y. Guan, D. Wei, H. Xiao, A. Zheng, A novel strategy for the preparation of long chain branching polypropylene and the investigation on foamability and rheology, European Polymer Journal, 48 (2012) 362-371.

[9] S. Abe, M. Yamaguchi, Study on the foaming of crosslinked polyethylene, Journal of applied 
polymer science, 79 (2001) 2146-2155.

[10] B. Wang, M. Wang, Z. Xing, H. Zeng, G. Wu, Preparation of radiation crosslinked foams from low - density polyethylene/ethylene - vinyl acetate (LDPE/EVA) copolymer blend with a supercritical carbon dioxide approach, Journal of Applied Polymer Science, 127 (2013) 912-918.

[11] M. Sauceau, J. Fages, A. Common, C. Nikitine, E. Rodier, New challenges in polymer foaming: a review of extrusion processes assisted by supercritical carbon dioxide, Progress in Polymer Science, 36 (2011) 749-766.

[12] P.C. Lee, J. Wang, C.B. Park, Extruded open-cell foams using two semicrystalline polymers with different crystallization temperatures, Industrial \& engineering chemistry research, 45 (2006) 175-181.

[13] A. Tsui, C.W. Frank, Impact of processing temperature and composition on foaming of biodegradable poly (hydroxyalkanoate) blends, Industrial \& Engineering Chemistry Research, 53 (2014) 15896-15908.

[14] C.P. Park, Foam Extrusion of Syndiotactic Polypropylene-Polyethylene Blends, Journal of Cellular Plastics, 38 (2002) 129-138.

[15] M. Yamaguchi, K.I. Suzuki, Rheological properties and foam processability for blends of linear and crosslinked polyethylenes, Journal of Polymer Science Part B: Polymer Physics, 39 (2001) 2159-2167.

[16] M. Mihai, M.A. Huneault, B.D. Favis, H. Li, Extrusion Foaming of Semi - Crystalline PLA and PLA/Thermoplastic Starch Blends, Macromolecular bioscience, 7 (2007) 907-920.

[17] S. Siripurapu, Y.J. Gay, J.R. Royer, J.M. DeSimone, R.J. Spontak, S.A. Khan, Generation of microcellular foams of PVDF and its blends using supercritical carbon dioxide in a continuous process, Polymer, 43 (2002) 5511-5520.

[18] X. Han, J. Shen, H. Huang, D.L. Tomasko, L.J. Lee, CO2 foaming based on polystyrene/poly (methyl methacrylate) blend and nanoclay, Polymer Engineering \& Science, 47 (2007) 103-111.

[19] X. Liao, H. Zhang, Y. Wang, L. Wu, G. Li, Unique interfacial and confined porous morphology of PLA/PS blends in supercritical carbon dioxide, RSC Adv., 4 (2014) 45109-45117.

[20] G. Zhang, Y. Wang, H. Xing, J. Qiu, J. Gong, K. Yao, H. Tan, Z. Jiang, T. Tang, Interplay between the composition of LLDPE/PS blends and their compatibilization with polyethylene-graft-polystyrene in the foaming behaviour, RSC Adv., 5 (2015) 27181-27189.

[21] D.F. Baldwin, C.B. Park, N.P. Suh, A microcellular processing study of poly(ethylene terephthalate) in the amorphous and semicrystalline states. Part I: Microcell nucleation, Polymer Engineering \& Science, 36 (1996) 1437-1445.

[22] D.F. Baldwin, C.B. Park, N.P. Suh, A microcellular processing study of poly(ethylene terephthalate) in the amorphous and semicrystalline states. Part II: Cell growth and process design, Polymer Engineering \& Science, 36 (1996) 1446-1453. 
[23] W. Zhai, H. Wang, J. Yu, J. Dong, J. He, Foaming behavior of polypropylene/polystyrene blends enhanced by improved interfacial compatibility, Journal of Polymer Science Part B: Polymer Physics, 46 (2008) 1641-1651.

[24] X. Liao, A.V. Nawaby, Y.P. Handa, Layered and cellular morphologies in atactic/syndiotactic polystyrene blends, Cellular polymers, 26 (2007) 69.

[25] O.M. Istrate, M.A. Gunning, C.L. Higginbotham, B. Chen, Structure-property relationships of polymer blend/clay nanocomposites: Compatibilized and noncompatibilized polystyrene/propylene/clay, Journal of Polymer Science Part B: Polymer Physics, 50 (2012) 431-441.

[26] X.L. Jiang, L. Tao, Z. Ling, Z.M. Xu, W.K. Yuan, Effects of Blend Morphology on the Foaming of Polypropylene/ Low-density Polyethylene Blends during a Batch Foaming Process, Journal of Cellular Plastics, 45 (2009) 225-241.

[27] C. Liu, J. Wang, J. He, Rheological and thermal properties of m-LLDPE blends with m-HDPE and LDPE, Polymer, 43 (2002) 3811-3818.

[28] G. Adebayo, P. Koombhongse, M. Cakmak, Raman spectroscopy as an on-line technique to monitor shear flow effect on partially miscible polymer blends, International Polymer Processing, 18 (2003) 260-272.

[29] J. Katsaros, M. Malone, H. Winter, The effects of flow on miscibility in a blend of polystyrene and poly (vinyl methyl ether), Polymer Engineering \& Science, 29 (1989) 1434-1445.

[30] J.S. Colton, N.P. Suh, The nucleation of microcellular thermoplastic foam with additives: Part I: Theoretical considerations, Polymer Engineering \& Science, 27 (1987) 485-492.

[31] J.S. Colton, N.P. Suh, Nucleation of microcellular foam: Theory and practice, Polymer Engineering \& Science, 27 (1987) 500-503.

[32] C. Fan, C. Wan, F. Gao, C. Huang, Z. Xi, Z. Xu, L. Zhao, T. Liu, Extrusion foaming of poly (ethylene terephthalate) with carbon dioxide based on rheology analysis, Journal of Cellular Plastics, 52 (2015) 277-298.

[33] W.-M. Ni, The mathematics of diffusion, siam, 2011.

[34] J. Chen, T. Liu, W.-k. Yuan, L. Zhao, Solubility and diffusivity of CO 2 in polypropylene/micro-calcium carbonate composites, The Journal of Supercritical Fluids, 77 (2013) 33-43.

[35] P. Scholz, D. Froelich, R. Muller, Viscoelastic Properties and Morphology of Two - Phase Polypropylene/Polyamide 6 Blends in the Melt. Interpretation of Results with an Emulsion Model, Journal of Rheology (1978-present), 33 (1989) 481-499.

[36] A.R. Nesarikar, Rheology of polymer blend liquid-liquid phase separation, Macromolecules, 28 (1995) 7202-7207.

[37] A. Muñoz-Escalona, P. Lafuente, J.F. Vega, M.E. Muñoz, A. Santamaría, Rheological behaviour of 
metallocene catalysed high density polytheylene blends, Polymer, 38 (1997) 589-594.

[38] J.D. Ferry, Viscoelastic properties of polymers, John Wiley \& Sons, 1980.

[39] N.K.B. Datta, A.W., Thermal analysis of polyethylene blends., Plastic and Rubber Processing and Application, 2 (1982) 9.

[40] G.M. Jordhamo, J.A. Manson, L.H. Sperling, Phase continuity and inversion in polymer blends and simultaneous interpenetrating networks, Polymer Engineering \& Science, 26 (1986) 517-524.

[41] J. Vlachopoulos, D. Strutt, The role of rheology in polymer extrusion, in: New Technology for Extrusion Conference. Milan, Italy. Nov, 2003, pp. 20-21.

[42] H.E. Naguib, C.B. Park, N. Reichelt, Fundamental foaming mechanisms governing the volume expansion of extruded polypropylene foams, Journal of applied polymer science, 91 (2004) 2661-2668.

[43] W. Zhai, H. Wang, J. Yu, J.-Y. Dong, J. He, Foaming behavior of isotactic polypropylene in supercritical CO 2 influenced by phase morphology via chain grafting, Polymer, 49 (2008) 3146-3156. 


\section{Graphical abstract}

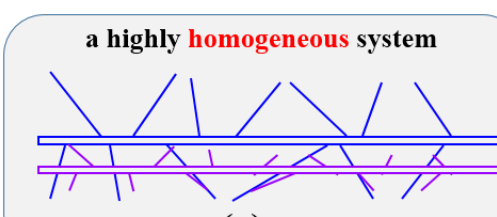

(a)

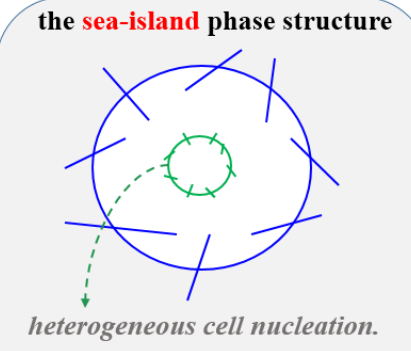

(b)

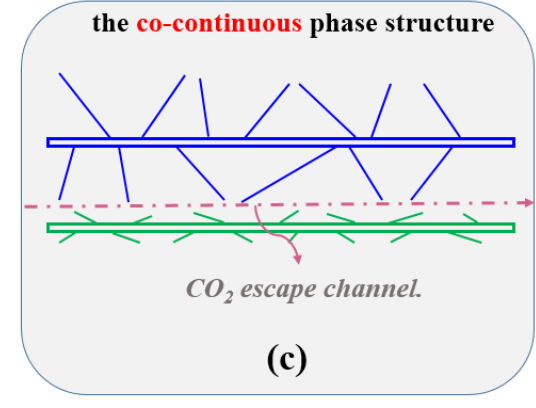

(c)

As illustrated above, for highly compatible LDPE/HDPE blends, the $\mathrm{CO}_{2}$ diffusion mechanism is analogous to those of single phase polymers. For those incompatible blends, the heterogeneous phase structure is beneficial to the cell nucleation. However, the channels formed at the phase interface are found to accelerate gas escape. 